\title{
Aspect-ratio dependent oscillatory thermocapillary convection in the floating half zone ${ }^{\dagger}$
}

\author{
AA Yan, LI Kai ${ }^{1,2}$, CAO ZhongHua ${ }^{1,2} \&$ HU WenRui ${ }^{1,2^{*}}$ \\ ${ }^{1}$ Key Laboratory of Microgravity, Institute of Mechanics, Chinese Academy of Sciences, Beijing 100190; \\ ${ }^{2}$ China and National Microgravity Laboratory, Institute of Mechanics, Chinese Academy of Sciences, Beijing 100190, China
}

Received November 2, 2010; accepted November 30, 2010; published online December 16, 2010

\begin{abstract}
The dependency of the critical Marangoni number on the geometrical aspect ratio of the floating half zone is essential to predict the onset of oscillatory thermocapillary convection. The experimental studies in the microgravity conditions on floating half zones of several centimeters in diameter have predicted that the critical Marangoni number increases with the increasing aspect ratio, and the terrestrial experimental studies have predicted the contradictory conclusion for floating half zones of several millimeters in diameter. In the present work, terrestrial experimental studies were conducted on the floating half zones of 5 Centistokes (cSt) silicon oil and $10 \mathrm{cSt}$ silicon oil. The experimental results show that the critical Marangoni number generally increases with the increasing aspect ratio of the floating half zone and then decreases. Moreover, a further increase of the critical Marangoni number with the increasing aspect ratio occurs for the slender floating half zones.
\end{abstract}

thermocapillary convection, flow instability, aspect ratio

PACS: $47.55 . \mathrm{nb}, 47.20 . \mathrm{Ky}, 47.27 . \mathrm{Cn}$

\section{Introduction}

In fluid systems with interface involved in the manned space activities, capillary effects play a dominant role in comparison with gravity effects. Among them, the thermocapillary convection driven by the surface-tension gradient along the interface becomes one of the fundamental subjects in the microgravity fluid physics and the space fluid/heat management [1]. A floating half zone consisting of a liquid column confined between differentially heated solid rods (see Figure 1) was initially introduced to mimic half of the floating zone technique for the interests of space materials science, and it has become one of the typical models for the investigation of the principles of thermocapillary convection. Originated by Chun and Wuest [2] and Schwabe et al. [3]

*Corresponding author (email: wrhu@imech.ac.cn)

†Contributed by HU WenRui respectively, extensive studies have shown that with the increasing applied temperature difference between the supporting rods, the thermocapillary convection transfers from the axisymmetric stationary convection to the oscillatory convection in the floating half zone of large Prandtl number $(\operatorname{Pr} \gg 1)$. The dependency of the critical Marangoni number indicating the onset of oscillatory convection on the aspect ratio of the floating half zone is one of the fundamental critical parameters involved in the bifurcation process [1]. The Marangoni number is defined as $M a=U l / \kappa$ where $U=\left|\sigma_{T}^{\prime}\right| \Delta T / \mu$ is the typical thermocapillary velocity, $\sigma_{T}^{\prime}$ the surface-tension gradient depending on the temperature, $\Delta T$ the typical temperature difference, $\mu$ the viscosity, $\kappa$ the thermal diffusivity of the fluid and $l$ the height of the floating half zone. Due to the scarce space experiment opportunities, most of the experimental studies available were conducted terrestrially. The relative importance of the gravity effects to the capillary effects is scaled 
by the static Bond number $\left(B_{0}=\rho g l^{2} / \sigma\right)$ or the dynamic Bond number $\left(B_{d}=\rho g \beta l^{2} /\left|\sigma_{T}^{\prime}\right|\right.$ ), where $\rho$ is the fluid density, $g$ the earth gravity level, $\beta$ the thermal expansion coefficient and $\sigma$ the surface-tension. Therefore, the geometrical scale of the floating half zone in the terrestrial conditions was reduced to several millimeters in diameter to make the capillary effects dominant. Among them, Velten et al. [4] predicted that the critical Marangoni number decreases with the increasing aspect ratio of the floating half zone $\left(A=l / d_{0}\right.$ where $d_{0}$ is the radius of the floating half zone). The tendency contradicts the experimental predictions on the floating half zones of several centimeters in diameter in the microgravity conditions (see Table I. in ref. [5]) where the critical Marangoni number increases with the increasing aspect ratio of the floating half zone.

On the other hand, theoretical studies in the early period on the onset of oscillatory thermocapillary convection were limited to a cylindrical floating half zone model. The terrestrial experiments did not investigate the effect of the volume of floating half zone either. In practice, a cylindrical floating half zone can be assumed only in the microgravity conditions, and the configuration of floating half zone in the terrestrial conditions should be similar to part of a calabash due to the Earth's gravity. Recent experimental and theoretical studies have shown that the volume of the floating half zone is another sensitive geometrical parameter involved in the bifurcation process [6-8]. For example, the marginal stability boundary for the oscillatory thermocapillary convection consists of two branches with the increasing volume of the floating half zone with a fixed diameter and an aspect ratio. In practice, a parameter noted as volume ratio $\left(V / V_{0}\right)$, i.e., the ratio of the volume of a floating half zone to that of a cylindrical one with the same height and diameter, is usually adopted to represent the effect of the volume.

The present paper experimentally studied the aspect-ratio dependent critical Marangoni numbers of the thermocapillary convection in the floating half zones of 5 Centistokes (cSt) silicon oil and $10 \mathrm{cSt}$ silicon oil respectively with different volume ratios.

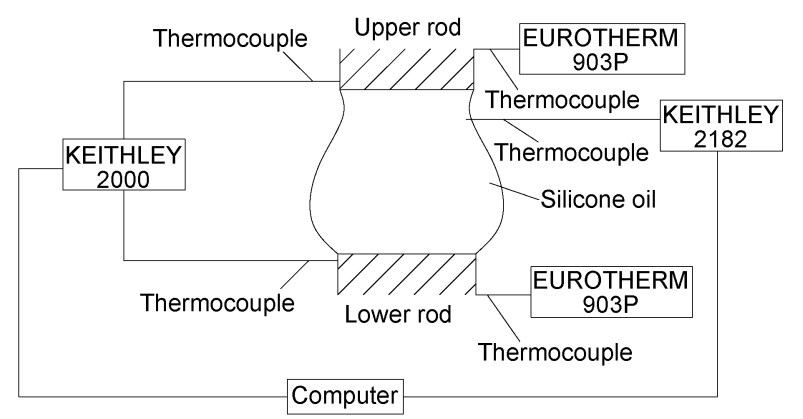

Figure 1 The schematic diagram of experimental facility.

\section{Experimental facility}

As shown in Figure 2, a floating half zone formed between two co-axial rods of the same diameter $\left(d_{0}\right)$. A temperature difference $(\Delta T)$ was gradually applied at a certain heating rate $\left(0.3 \mathrm{~K} \mathrm{~min}^{-1}\right)$ between the supporting rods, and the upper rod was always kept at the higher temperature. Two PID-controllers (EUROTHERM 903P controller) were used to control the heating rate that enabled the applied temperature difference measured by two thermocouples of T-type (see Figure 1) to have an accuracy better than $0.05 \mathrm{~K}$. A thermocouple of the K-type $(0.02 \mathrm{~mm}$ in diameter $)$ was inserted into the liquid column at $0.8 \mathrm{l}$ above the lower rod and right beneath the free surface, and the corresponding local temperature change was registered by a KEITHELY 2182 with a resolution of $0.001 \mathrm{~K}$. Another two thermocouples of the T-type were attached to the rods in the vicinity of the rod/liquid interface, and the corresponding temperature signals were registered by a multi-meter KEITHELY 2000 with a resolution of $0.01 \mathrm{~K}$. Time series of the temperature signals are transformed in the frequency domain by FastFourier-Transformation (FFT) in real time. The temperature signals and the corresponding spectra could be observed
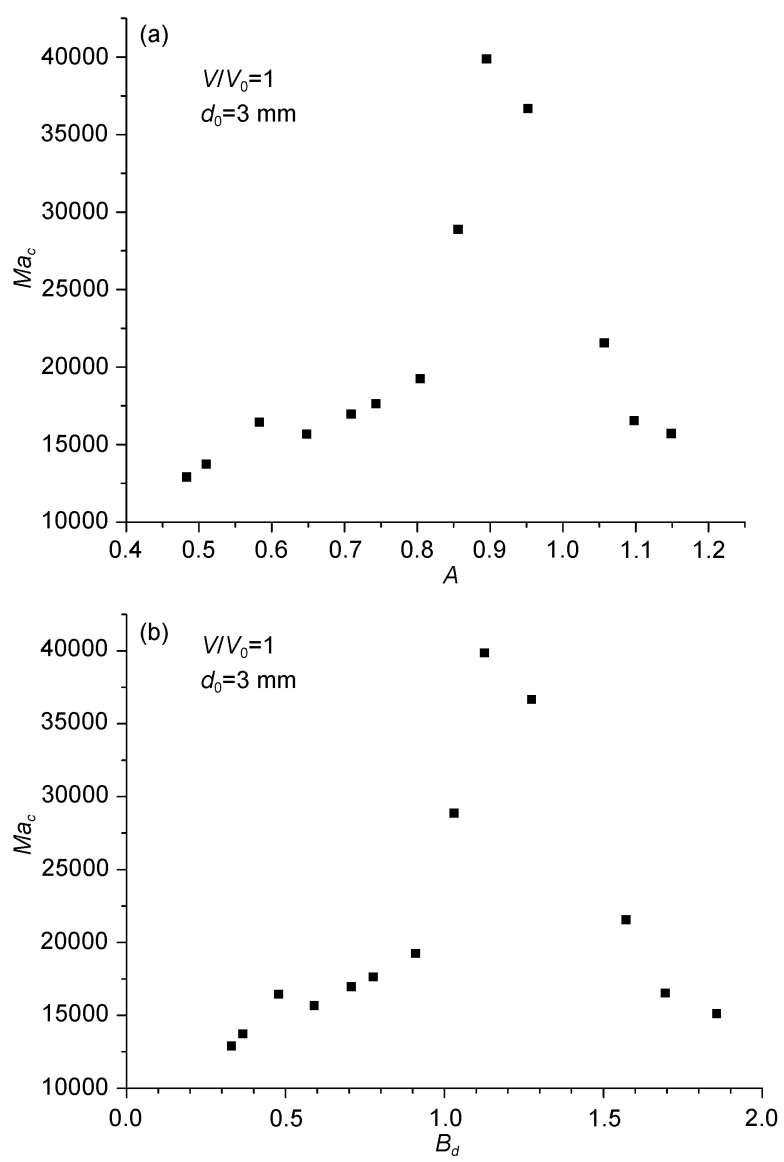

Figure 2 The critical Marangoni number depending on (a) the aspect ratio and (b) the dynamic Bond number in the floating half zone of $10 \mathrm{cSt}$ silicon oil with $V / V_{0}=1.0$. 
through the computer monitor both online and offline. The experiment process is also controlled by the same PC-supported data acquisition system. The onset of oscillatory thermocapillary convection is detected through the temperature evolution obtained by the KEITHELY 2182. With the increasingly applied temperature difference, the temperature signals can be observed to transfer from an approximately steady state into an oscillatory state. The applied temperature difference at the transition moment is adopted as the critical temperature difference $\left(\Delta T_{c}\right)$. For each floating half zone with a fixed diameter, the aspect ratio is varied through adjusting the height of floating half zone. On the other hand, the volume of the floating half zone can be obtained through a measurement system consisting of a CCD camera and a PC with an image-acquiring card. The boundaries of the floating half zone are defined by processing its images, and then the volume of floating half zone can be calculated and the injection of the silicon oil before the onset of the oscillatory convection allows the compensation of the volume change due to the thermal expansion and evaporation. The uncertainty in the determination of the critical Marangoni number in the present study is $\pm\left(0.01 M a_{c}+\left(2 / \Delta T_{c}\right) M a_{c}\right)$ where the former is from the measurement of the geometry of the floating half zone and the latter is from the measurement of the critical temperature difference. The measurement of the critical Marangoni number for the same parameters was repeated several times and the averaged value is finally adopted.

In the present experimental study, the floating half zones of $5 \mathrm{cSt}$ silicon oil $(\mathrm{Pr}=\mu / \rho \kappa=74)$ and $10 \mathrm{cSt}$ silicon oil $(\mathrm{Pr}$ $=106)$ were studied, and the typical volume ratios of $V / V_{0}=$ 1.0 and $V / V_{0}=0.7$ were adopted.

\section{Experimental results and discussion}

Figure 2 shows the experimentally determined marginal stability boundary for the floating half zone of $5 \mathrm{cSt}$ silicon oil $(\operatorname{Pr}=74)$ with $d_{0}=3 \mathrm{~mm}$ and $V / V_{0}=1.0$. In the range of $A \leqslant 0.58$, the critical Marangoni number increases with the increasing aspect ratio. In the range of $0.58 \leqslant A \leqslant 0.74$, the critical Marangoni number is nearly constant in consideration of the critical Marangoni number uncertainty \pm 892 for the case of $A=0.65$. This phenomenon is different from the experimentally predicted decreasing tendency in [4]. The critical Marangoni number then sharply increases in the range of $0.74 \leqslant A \leqslant 0.90$ which qualitatively agrees with the experimental predictions on the floating half zone of several centimeters in diameter (see Table I. in ref. [5]). The similar tendency in the range of $0.58 \leqslant A \leqslant 0.90$ was also experimentally observed in [9-11]. The increasing steepness of the profile may be due to the increasing role of the buoyancy convection in the floating half zone which stabilizes the thermocapillary convection. Furthermore, in the range of $0.90 \leqslant A \leqslant 1.15\left(B_{d}>1\right)$ the critical Marangoni number appreciably decreases. For the decreasing trend we speculate that with the increasing free-surface deformation at the large dynamic Bond number, the decreasing effective aspect ratio results in the preferential oscillation mode change of the thermocapillary convection. However, further investigations require detailed velocity information which is limited in the present experimental study.

Figure 3 shows the experimentally determined critical Marangoni number for the floating half zone of $10 \mathrm{cSt}$ silicon oil $(P r=106)$ with $V / V_{0}=1.0$. The general tendency of the marginal stability boundary for the case of $d_{0}=3 \mathrm{~mm}$ is similar to the case of $5 \mathrm{cSt}$ silicon oil. The effect of the diameter of the floating half zone is also investigated (see Figure 3). The general tendency of the marginal stability boundaries for the floating half zones of $d_{0}=4-6 \mathrm{~mm}$ is similar to the case of $d_{0}=3 \mathrm{~mm}$ except that the critical Marangoni number approximately increases continuously with the increasing aspect ratio. Note that in the narrow range of $0.80<A<0.87$ in the case of $d_{0}=4 \mathrm{~mm}, 0.72<A<0.78$ in the case of $d_{0}=5 \mathrm{~mm}$ and $0.55<A<0.68$ in the case of $d_{0}=6 \mathrm{~mm}$
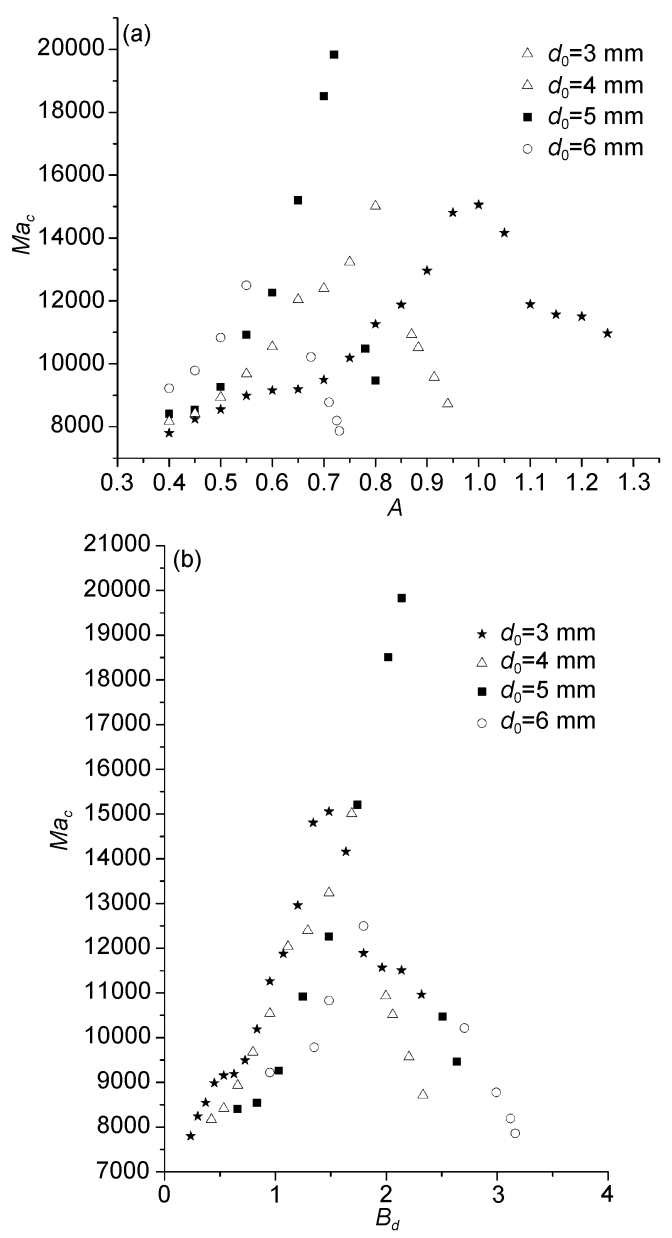

Figure 3 The critical Marangoni number depending on (a) the aspect ratio and (b) the dynamic Bond number in the floating half zone of $10 \mathrm{cSt}$ silicon oil with $V / V_{0}=0.7$. 
respectively, the experimental data are unavailable due to the breakage of the floating half zone. However, it still can be seen that for the floating half zones of different diameters, the transition between the increasing branch and the decreasing branch occurs in the approximately same range of $1.48<B_{d}<2.13$ where the buoyancy effects, related to the thermocapillary effects in the floating half zone, including the buoyancy convection and the free-surface deformation become important.

The experimental studies were also conducted on the floating half zones of $10 \mathrm{cSt}$ silicon oil $(\operatorname{Pr}=106)$ with $V / V_{0}=$ 0.7. Figure 4 shows the corresponding aspect-ratio dependent marginal instability boundaries. Similar to the case of 10 cSt silicon oil with $V / V_{0}=1.0$, the critical Marangoni number increases with the increasing aspect ratio and then decreases. However, the transition between the increasing branch and the decreasing branch occurs in the range of $B_{d}<1$, which probably excludes the possibility of the preferential oscillation mode change of the thermocapillary convection as our

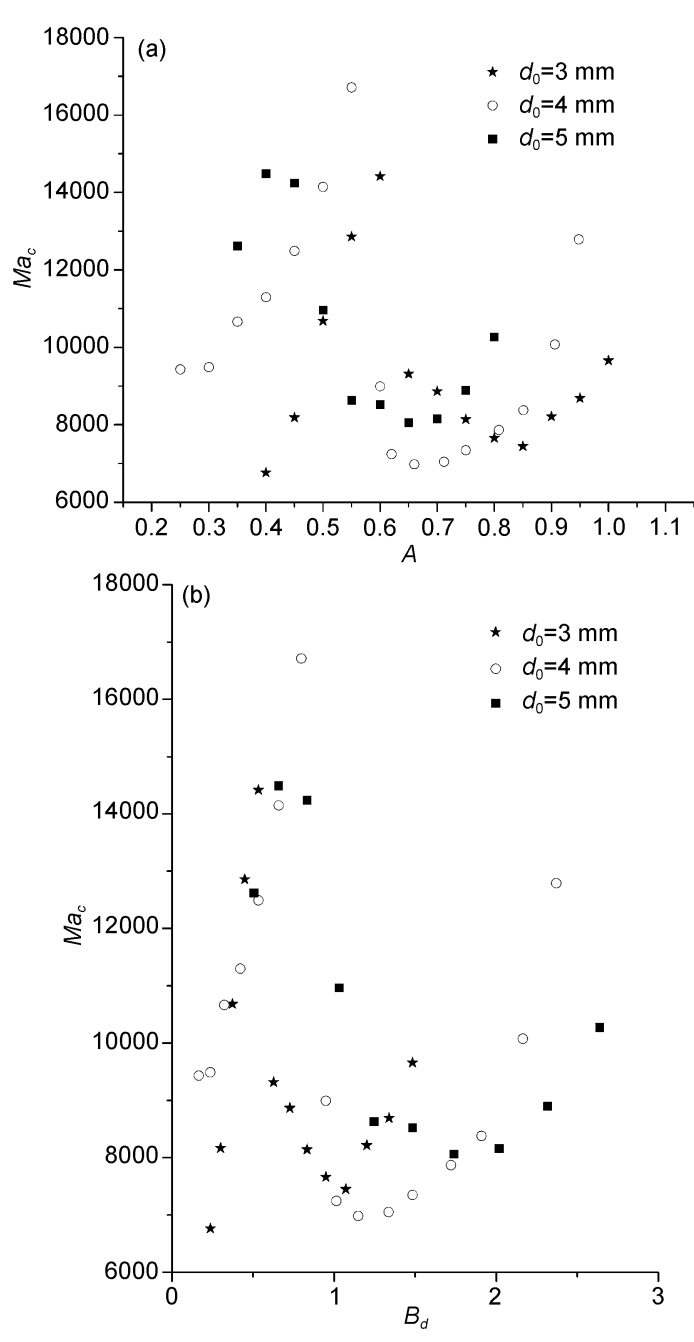

Figure 4 The critical Marangoni number depending on (a) the aspect ratio and (b) the dynamic Bond number in the floating half zone of $5 \mathrm{cSt}$ silicon oil with $V / V_{0}=1.0$. interpretation of the transition. It is also noted that the decreasing branch is followed by a further increase branch with the increasing aspect ratio, e.g., $A>0.85$ in the case of $d_{0}=3 \mathrm{~mm}$. However, the present experimental study provides no clue as to the general trend of the marginal stability boundary for the slender floating half zones of $V / V_{0}=0.7$, which requires further delicate experimental studies for the velocity information and numerical studies as well.

\section{Summary}

In the present paper, the dependency of the marginal instability boundary on the aspect ratio of floating half zones was studied experimentally and terrestrially. For the floating half zones of $5 \mathrm{cSt}$ silicon oil and $10 \mathrm{cSt}$ silicon oil with $V / V_{0}=1.0$, the experimental results show that the critical Marangoni number generally increases with the increasing aspect ratio of the floating half zone and then decreases. The transition is probably due to the increasing buoyancy effects including the buoyancy convection and the free-surface deformation with the increasing aspect ratio or the dynamic Bond number. On the other hand, Moreover, for the floating half zones of $10 \mathrm{cSt}$ silicon oil with $V / V_{0}=$ 0.7, a further increase of the critical Marangoni number with the increasing aspect ratio occurs, which requires further investigations.

This work was supported by the National Natural Science Foundation of China (Grant No. 11032011) and Knowledge Innovation Project of the Chinese Academy of Sciences (Grant No. KJCX2-YW-LO8).

1 Hu W R, Tang Z M, Li K. Thermocapillary flow in floating zones. Appl Mech Rev, 2008, 61: 010803

2 Chun C H, Wuest W. A micro-gravity simulation of the Marangoni convection. Acta Astronaut, 1978, 5: 681-686

3 Schwabe D, Scharmann A, Preisser F, et al. Experiments on surface tension driven flow in floating zone melting. J Cryst Growth, 1978, 43: 305-312

4 Velten R, Schwabe D, Scharmann A. The periodic instability of thermocapillary convection in cylindrical liquid bridges. Phys Fluids A, 1991, 3: 267-279

5 Carotenuto L, Castagnolo D, Albanese C, et al. Instability of thermocapillary convection in liquid bridges. Phys Fluids, 1998, 10: $555-565$

$6 \mathrm{Hu} \mathrm{W} \mathrm{R,} \mathrm{Shu} \mathrm{J} \mathrm{Z,} \mathrm{Zhou} \mathrm{R,} \mathrm{et} \mathrm{al.} \mathrm{Influence} \mathrm{of} \mathrm{liquid} \mathrm{bridge} \mathrm{volume} \mathrm{on}$ the onset of oscillation in floating zone convection I. Exp J Cryst Growth, 1994, 142: 379-384

7 Tang Z M, Hu W R. Influence of liquid bridge volume on the onset of oscillation of floating zone convection II. Numerical simulation. J Cryst Growth, 1994, 142: 385-391

8 Tang Z M, Hu W R. Influence of liquid bridge volume on the onset of oscillation in floating zone convection III. Three-dimensional model. J Cryst Growth, 1999, 207: 239-246

9 Preisser F, Schwabe D, Scharmann A. Steady and oscillatory thermocapillary convection in liquid columns with free cylindrical surface. J Fluid Mech, 1983, 126: 545-567

10 Kamotani Y, Ostrach S, Vargas M. Oscillatory thermocapillary convection in a simulated floating-zone configuration, half-zone liquid bridge. J Cryst Growth, 1984, 66: 83-90

11 Ueno I, Tanaka S, Kawamura H. Oscillatory and chaotic thermocapillary convection in a half-zone liquid bridge. Phys Fluids, 2003, 15: $408-416$ 